\title{
An analysis of the household energy rebound effect from a practice perspective: spatial and temporal dimensions
}

\author{
Tanja Winther • Harold Wilhite
}

Received: 17 December 2013 / Accepted: 20 October 2014 / Published online: 30 October 2014

(C) The Author(s) 2014. This article is published with open access at Springerlink.com

\begin{abstract}
This article presents and discusses results from an empirical study of people's uses of various types of heat pumps in Norwegian homes. We analyze the rebound effect from a practice theory perspective. In-depth interviews were conducted with 28 homes in 2012 and 2013, and in two cases, we observed the process and aftermath of the installations of heat pumps. We disentangle the motives behind people's acquisition of heat pumps and examine how heat pumps are taken in use, that is, the ways heat pumps form part of - and modify - the social practices into which they are integrated, whether related to heating, comfort, time management, or other routines and concerns. The results show that a comfort rebound effect (direct rebound) is at work in two specific senses. First, a "temporal rebound" occurs as people expand the amount of time the home is heated. Secondly, the heat pump enables a physical expansion of the heated space, which we refer to as the "spatial rebound". We show that three sources of agency contribute to these shifts: people's own practical knowledge, expert knowledge, and the heat pump's embedded script. Our findings indicate that the ways that heat pumps are viewed and used differ significantly
\end{abstract}

The authors are associated with CREE - the Oslo Centre for Research on Environmentally friendly Energy — which is supported by the Research Council of Norway.

T. Winther $(\bowtie) \cdot H$. Wilhite

Centre for Development and the Environment (SUM),

University of Oslo,

Sognsveien 68, P.O. Box 1116, Blindern N-0317 Oslo,

Norway

e-mail: tanja.winther@sum.uio.no between the suppliers who promote them and the households who buy and use them.

Keywords Energy savings $\cdot$ Households $\cdot$ Heating $\cdot$ Heat pumps $\cdot$ Rebound effect $\cdot$ Temporal and spatial dimensions · Comfort - Convenience · Practical knowledge Expert knowledge Practice theory . Qualitative research

\section{Introduction}

The "rebound effect" is a term used to characterize a paradox or anomaly in energy saving policies and programs: the purchase and use of an energy efficient appliance seldom leads to the anticipated reduction in household energy consumption. Research efforts on why there is rebound in consumption and whether there are ways to avoid or diminish the rebound have most often been conducted from an economic perspective, looking at costs, reinvestment, and substitution effects of a purchase. In this paper, we explore rebound from a social practice perspective. Drawing on research conducted in the greater Oslo region in 2012 and 2013, we focus on Norwegian households who have installed a heat pump and examine the ways in which the new technologies affect heating practices as well as other related practices such as time management, comfort, and convenience. How and why do practices change, and specifically, what are the causes of rebound in energy consumption? We begin with a brief review of theoretical approaches to studying rebound, drawing 
attention to an approach grounded in social practice theory. We then discuss our methodology and give a summary of findings, beginning with people's expressed motivations for acquiring a heat pump and further how they perceive and interact with the heat pump in everyday life. We show that there is considerable discrepancy between the way heat pumps and their effects are presented by suppliers and how they are perceived by the users. We conclude with tentative thoughts on the implications of our study for energy saving policy.

\section{Theoretical approaches to rebound}

The concept of rebound can be traced back to the work of Jevons in the nineteenth century (Jevons 1865). He wrote that in a capitalist growth economy, money saved as a result of reducing the direct energy costs of energyusing technologies and equipment would be invested in other energy using products or practices, the net result of which is a decline in anticipated energy savings or even an increase in energy use. This so-called paradox has been a ghost that has haunted energy saving policy since such policies emerged after the oil embargos of the 1970s. A persistent and overarching goal in this policy domain has been to encourage the diffusion of energy efficient technologies. However, empirical evidence from the 1980s and onwards suggests that the Jevons paradox is at work in spoiling potential energy efficiency gains (for reviews and examples, see Brannlund et al. 2007; Sorrell et al. 2009; Turner 2009).

Whereas one can discuss the rebound effect at the macro-economic level, where rebound in a growth economy is regarded as positive, it also occurs in places where energy is consumed and where it is presumably saved through the installation of energy efficient equipment. There is widespread agreement among those who have researched the consumption rebound effect that it takes two forms. The direct rebound effect is used to describe the situation in which money saved from the installation of an energy efficient technology such as an efficient heating system is used to buy more of the same service, such as heating more floor space or increasing the thermostat setting. The indirect rebound is when the saved money is used to finance some other energy using activity, such as purchasing other appliances or travelling more.
According to a recent review of the rebound literature by Dutschke et al. (2013), there is widespread agreement that these rebound effects exist, but there is disagreement regarding the dimensions of the rebound and little knowledge about what people actually do when they rebound. Furthermore, most of the research on consumption rebound has focused on transport. Very few studies have focused on inside-the-home rebounds, and these have mainly had an economic framing, examining price elasticities as well as other price and income effects associated with rebound (Thomas and Azevedo 2013; Frondel et al. 2012; Fouquet and Pearson 2012; Biswanger 2001). Aside from economics, the main contributions to studying rebound have come from social psychologists, who have examined the role of changing attitudes, norms, and social behaviors in fostering rebound (de Haan et al. 2006; Hofstetter et al. 2006; Dutschke et al. 2013).

In this study, we approach rebound from a social practice perspective, drawing on efforts over the past decade to apply practice theory to an understanding of home energy consumption (see for example Warde 2005; Gram-Hanssen 2010, 2014; Halkier et al. 2011; Wilhite 2013). Practice theory has its roots in the work of Bourdieu $(1977,1998)$ and his concept of habitus, defined as a domain of dispositions for action, created and perpetuated through the repeated performance of actions in a given social and cultural space. These dispositions constitute a form for knowledge which influences subsequent performances of the same action. This conceptualization contrasts dramatically with cognitive and rational choice-based theories of action which dominate energy research. A widely cited practice theorist, Andreas Reckwitz, defines a practice as "a routinized type of behavior which consists of several elements, interconnected to one another: forms of bodily activities, forms of mental activities, "things" and their use, a background knowledge in the form of understanding, know-how, states of emotion and motivational knowledge" (2002, p. 249, cited in Warde 2005). Thus, practice theory views knowledge as a property of both mind and body and in fact is not overly concerned with the division. It takes account of the fact that many consumption actions have histories, both at the societal and individual levels. As practices are repeated through lived experience, dispositions for future actions develop and become agentive. Everyday life in Norway and other OECD countries is replete with energydependent practices; yet, mainstream theory of both 
behavior and rebound have been dominated by assumptions of rational consumers who respond to deductive information in the form of prices and paybacks on energy investments based on saved energy over time. Little attention has been given to experiential knowledge and a theory of change that acknowledges practical learning in everyday consumption practices such as travel, indoor comfort (cooling and heating), and the acquisition and preparation of food.

Once purchased and taken into use, household technologies such as refrigerators, cooking appliances, washing machines, and heat pumps bear with them the potential to reshape practices. Madeleine Akrich (1994), working in the Science of Technology Studies (STS) tradition, designates this potential as a "technology script", by which she means that technologies have embedded potentials which can be activated in practices and thus influence actions. In other words, technologies bring with them their own set of dispositions or "scripts" for practices (see Wilhite 2008 for a discussion). Thus, one can say that changes in practice are influenced by practical knowledge grounded in routinized behavior, by reflexive knowledge associated with evaluating economic and technical issues, including advice from installers, and scripts that are embedded in the technology. These sources of knowledge are the subjects of research in a social practice framework.

To date, only a smattering of rebound studies have applied a social practice perspective. Herring (2011) advocates the use of a practice framework but does not apply it in an empirical study. Christensen et al. (2011) used a practice approach to examine rebound effects of air-to-air heat pumps in Denmark. In a large quantitative sample, they were able to identify energy savings in homes that had installed heat pumps, but the savings were far below predictions based on purely technical estimations. Using data from the sample of 76 households, they found that about half of the sample reported that they "kept temperatures generally higher" after installation. Also, about half of the sample reported that they used heat "for a longer period of the year than previous". Interviews were done with a small sample of eight households in order to contextualize why these heating changes were made and to identify other practices that were associated with the installation. One important finding from the qualitative sample was that heat pumps were often installed in conjunction with a larger home renovation or improvement project in which the space of the home was expanded. The
Danish study provides tantalizing evidence for the power of a practice perspective to elicit new knowledge about rebound. However, the qualitative sample was small, and the ambitions limited regarding the changes in non-heating-related practices.

In our study, an effort has been made to both broaden the scope of the study of changes in practice associated with heat pumps and to give special attention to the ways that heat pumps affect comfort practices. We deploy an understanding of comfort developed through the work of Shove (2003) and Wilhite et al. (1996), who show that comfort consists not only of a physiological component but also a very strong social component. Notions of what constitutes an ideally heated home vary dramatically by region of the world and over time, though as Shove demonstrates, comfort-related energy demands are expanding almost everywhere. In Norway, a well-heated living space is considered one of the central components of "coziness", a highly sought after home aesthetic on cold winter evenings. As we will explore below, for Norwegians, the heat pump enables an expansion in time and space of a warm and cozy indoor environment.

\section{The research design and methods}

Our empirical data derives from 28 in-depth interviews with Norwegian households conducted in their homes and from conversations with a technical expert who installs and maintain heat pumps on behalf of a supplier. In two of the homes, we observed the installation of the heat pump. In the remainder of the sample, one family had recently moved into a home with a heat pump, and the others (25) had been using their pumps for more than a year. The respondents were recruited in two rounds. In the first round, we selected people who had participated in a national survey that had been conducted by Statistics Norway (SSB) in 2009. ${ }^{1}$ The selection criteria were primarily based on people's geographic location (proximity to the researchers' own location) and their willingness to participate. A letter of invitation for interview was sent to all the 97 respondents in the SSB survey who had reported having a heat pump (of any kind) and who lived in Oslo or the neighboring county

\footnotetext{
${ }^{1}$ The Norwegian Survey of Consumer Expenditures for the year 2009 and an additional questionnaire concerning energy consumption (Halvorsen and Larsen 2013).
} 
Akershus. In the letter, we encouraged as many family members as possible to be present during the interview. The participants were informed that they would be given a gift card worth 62 euros (500 NOK) as compensation. Based on this procedure, 14 families in Oslo and Akershus responded and were interviewed in their homes in January and February 2013. Putting these together with the results of a test interview conducted in Oslo, there were altogether 15 first round interviews. The second round of 13 interviews was accomplished in June and July 2013. ${ }^{2}$ Two of these families (in Oslo) were recruited through a supplier, and the remaining 11 families were recruited through our research assistant's social network, though none of the interviewees are related to her personally. ${ }^{3}$ Four of these families live in Vestfold (ca $150 \mathrm{~km}$ south of Oslo) and seven are located in Trønderlag (500 km north of Norway, in the towns of Namsos and Trondheim). Table 1 provides a summary of the sample's characteristics and whom we interviewed. All the families live in some form of detached house with a chimney, thus having access to the use of wood (oven or fireplace). In addition to using electricity for running the heat pump, almost all respondents have and use electric floor heating cables in bathrooms (and in a few cases also other rooms) and electric resistance ovens (Norwegian: panelovner) in several rooms.

The interviews were conducted in people's homes and lasted from 30 to $90 \mathrm{~min}$. After asking for general information about family size, type of dwelling, duration of residence, and time of acquisition, the interviewees were invited to explain their motivation for purchasing the heat pump, how and from whom they had learned how to use it, and how they interact with the heat pump in daily life and in various seasons. We also focused on how this type of heating practice relates to and potentially affects other home heating practices, how the heating pumps are being used in combination with other heating sources, as well as other routines and concerns such as comfort, time management, and

\footnotetext{
$\overline{2}$ In this round, one of the researchers participated during the first interview, and a research assistant conducted 12 interviews by herself.

${ }^{3}$ We do not consider the link between interviewer and interviewees in these cases as having caused a problem with regard to the validity and reliability of the data. On the contrary, as the transcripts revealed and a point generally recognized in qualitative research, establishing a good relation in the interview setting enhances the probability for making respondents relax, be interested, and openly share their views.
}

Table 1 Selected characteristics of the 28 families interviewed

\begin{tabular}{|c|c|c|}
\hline $\begin{array}{l}\text { Geographic location, all in } \\
\text { Norway }\end{array}$ & $\begin{array}{l}\text { Oslo and Akershus } \\
\text { Vestfold } \\
\text { Trønderlag }\end{array}$ & $\begin{array}{l}17 \\
4 \\
7\end{array}$ \\
\hline \multirow[t]{3}{*}{ Type of home/building } & Detached & 26 \\
\hline & Semi-detached & 1 \\
\hline & Flat in detached house & 1 \\
\hline \multirow[t]{2}{*}{ Type of tenure } & Own & 27 \\
\hline & Rent & 1 \\
\hline \multirow[t]{4}{*}{$\begin{array}{l}\text { Time of installation, heat } \\
\text { pump }\end{array}$} & $\begin{array}{l}\text { About to be installed/just } \\
\text { moved in }\end{array}$ & 3 \\
\hline & $1-2$ years & 8 \\
\hline & $3-5$ years & 12 \\
\hline & $6-15$ years & 5 \\
\hline \multirow[t]{3}{*}{ Type of heat pump ${ }^{a}$} & Air to air & 22 \\
\hline & Air to water & 2 \\
\hline & Geothermal, water to water & 4 \\
\hline \multirow[t]{3}{*}{ Family status (adults) } & Only male & 1 \\
\hline & Only female & 2 \\
\hline & Both male and female & 25 \\
\hline \multirow{3}{*}{$\begin{array}{l}\text { Adult respondents per } \\
\text { interview }\end{array}$} & Male & 4 \\
\hline & Female & 8 \\
\hline & Both male and female & 16 \\
\hline \multirow[t]{3}{*}{ Age of respondents } & $20 \mathrm{~s}$ and $30 \mathrm{~s}$ & 6 \\
\hline & $40 \mathrm{~s}$ and $50 \mathrm{~s}$ & 13 \\
\hline & $60 \mathrm{~s}$ and $70 \mathrm{~s}$ & 9 \\
\hline \multirow[t]{2}{*}{ Children living at home } & Yes & 15 \\
\hline & No & 13 \\
\hline
\end{tabular}

${ }^{a}$ With the use of a relatively small amount of electricity, heat pumps extract and transfer heat from natural heat sources in the surroundings such as the air, ground, or water. The three types of pumps kept by respondents in this study included the use of outdoor air as a source for heating indoor air (air to air), outdoor air for heating water indoors (air to water) and geothermal heat from the ground connected to a water circulating system in the house by way of radiators or pipes under the floors (geothermal)

convenience. We also touched on wider issues such as their degree of environmental concern and views on energy policy. Finally, the potential for economic gain (saving money) was discussed, and we asked to what extent people were aware of how they spend the extra money if they manage to save energy. Although some kept a record of how much energy they used and might have saved (see below), none of our respondents were able (or willing) to tell us what the saved money had been spent on. "It all goes down the big drain", was a typical statement. This absence of an overview over 
how potential savings might have been spent makes it difficult to assess the indirect rebound effect, i.e., what kinds of consumption increase resulted from money savings attributable to the pump.

While bringing up these topics, we gave room for reflection and sought to follow up on people's statements. Participants were aware that we were researching from an energy saving perspective, and this might have led them to bias their answers. We tried to compensate for this by asking both open-ended questions and questions that demanded a specific response (e.g., "Do you sometimes turn off the heat pump? When? At what times during the day and over the year? Why/why not?"). Also, we invited participants to be reflexive. Toward the end of the interview, we explained the direct rebound effect and asked the interviewees to comment on the hypothesis that savings from the heat pump might lead to increased indoor temperature or other increases in energy use, the responses to which we discuss below.

The interviews were recorded and transcribed. The findings were coded manually, and a table was created which summarized the most important themes that came up during the analysis. These themes partly derived from the selection of questions asked during the interviews, but new themes also emerged and were systematized during the analysis, such as people's preexisting sources for heating and how the heat pump affects management of time and use of space. The following sections are structured so as to highlight the most important findings of this openly attuned qualitative study of rebound.

\section{Respondents' explanations for why they purchased a heat pump}

Most respondents gave a mix of reasons when explaining why they had obtained their heat pump. Among the 25 families who had purchased a heat pump, ${ }^{4}$ four families gave purely economic reasons, emphasizing its potential for saving money. Others had also weighed the costs and/or thought about potential

\footnotetext{
${ }^{4}$ Three families had moved into a house in which a heat pump was already in place. The investment cost for air-to-air heat pumps tended to be approximately 2.500 to 3.000 euros (20.000 to 25.000 NOK). For the other heat pump systems (water carried heat), the costs had sometimes included new floors; thus, the exact cost of pump and drilling was difficult to establish, but 8.750 to 18.800 euros (70.000 to $150.000 \mathrm{NOK}$ ) were sums that were mentioned.
}

savings while deciding to buy the pump. The heat pump's capacity to provide increased heating comfort was also frequently reported by most respondents as a reason for the acquisition. Four referred solely to the need "to get warmer" or to "obtain a more stable temperature", thus referring uniquely to comfort. Our material indicates that people's concern for comfort plays at least an equally important role as financial considerations when they decide to acquire a heat pump. Moreover, as we show below, the emphasis on comfort (rather than savings) became even stronger as the families recounted their daily experiences with the pump. In line with the Danish study (Christensen et al. 2011), we find that people are more concerned with potential financial gains at the time of investment than in daily life when the heat pump has been taken into use, when other concerns are in focus.

The existing building structure and heating system (i.e., the socio-material context) influence people's decision to buy a heat pump in important ways. Looking at the 25 families who had purchased a heat pump, seven were concerned with getting rid of their oil-heated system. ${ }^{5}$ Some of them mentioned that they expect oilbased heating to become banned in Norway in the near future; ${ }^{6}$ many said they had been concerned with high and shifting fuel oil prices, and others said they felt comfortable shifting from fossil to renewable heating sources for environmental reasons. Aesthetics and safety were also given as reasons for removing the oil heaters. An interesting observation is that many people viewed their possession and use of a heat pump as defining them as green and providing a rationale for increasing their use of heating energy. One woman said: "It's very special to feel like being environmentally friendly and staying in a house heated to 23 degrees [Celsius]." Twelve of the 25 families had introduced the heat pump in conjunction with a home renovation (11 families) or the construction of a new home (one family). Three of them had expanded the physical space of the home in the process, which partly supports findings from the Danish study accounting for the rebound effect (Christensen et al. 2011) and also those of Maller et al. (2012) who found that people in Melburn, Australia,

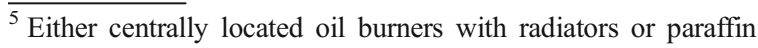
stoves.

${ }^{6}$ Through Enova, a public enterprise owned by the Ministry of Petroleum and Energy, the Norwegian government has launched a campaign and intends to phase out the use of oil burners in Norway by 2020 (Enova 2013).
} 
tend to enlarge their homes when renovating. Another two families had poorly functioning heating devices (old wood oven and Eswa electric cables in the ceiling) which needed replacement. Only seven families of those who purchased a heat pump had kept the existing structure of the house as it was and simply added the heat pump to be used in combination with (and partly substituting the use of) electric resistance ovens and wood stoves. The motivation for the families who made major changes was multifaceted, as indicated above. Some had felt "forced" to change the heating system either because of perceptions of forthcoming regulations, because their old technology was considered inappropriate/costly/useless and/or because they were in a phase in which larger changes were desired. Potentially, of course, thinking about investing in a heat pump may also have triggered an interest in initiating a renovation project. The accounts we received nonetheless underscore that heat pump installments seem to be associated with larger renovations involving an expansion of the size of the home. The expanded space obviously demands more heating energy and is a source of rebound.

\section{Practical knowledge associated with comfort, convenience and safety}

Most of the families in the study had previously used wood stoves or fireplaces to provide additional heat during cold periods. We found that heat pump owners continue to use wood stoves, though less frequently. They said they do so to save money on electricity (heat pump) and to supplement the heat pump's capacity to provide heat during very cold periods. There is also an aspect of coziness associated with wood stove (see below). But, there were many complaints about the lack of comfort offered by wood-based heating, such as the discomfort associated with starting a fire on a cold winter morning or when returning to a cold house from work, because it took time to prepare the fire and for it to produce heat. Several pointed out how the temperature is difficult to control with wood-based heating, especially overheating. One family who normally keeps the airto-air heat pump on at $23^{\circ} \mathrm{C}$ day and night compared the heat pump with wood heating in this way: “... [with the heat pump] it's easier to control the temperature because with wood either its cold or its damn hot." Similar complaints were made about the former oil burner: "It would become too hot inside and we were obliged to open the windows for relief." Many referred to the cozy atmosphere provided by wood stoves and fireplaces. However, when having guests over, several respondents found that the heat from wood-burning would become uncomfortably high: "it looks quite good with the fire on, but it's not a good way of heating when you've got guests". One family had solved this issue and was pleased with their modern wood stove/fireplace enclosed with a glass cover, which produces very little heat. This makes it possible to keep the fireplace going when visitors are present.

In terms of convenience, several families highlighted the time and effort they had had to use fetching wood from outside the house while at the same time trying to do other tasks, such as cooking and attending to children. Similar comments were made about the hassle people had experienced when filling up the oil tank and organizing the supply of oil. With regard to small children (below school age) and their comfort, one elderly couple said that the heat pump enables their visiting grandchildren to wake up to a reasonable temperature for watching television on weekend mornings. They had previously had to wake up early to start the wood stove.

In sum, the most important qualities of the heat pump for most of the families interviewed are the added comfort and convenience, as well as added safety for those who formerly relied on wood and oil. Compared with the relatively physically demanding set of tasks of starting and attending to a fire, the heat pump's remote control function is considered easy to handle. Nonetheless, apart from the cases where oil systems were replaced, people continue to use wood stoves and electric resistance ovens, though to a lesser extent than before. It is precisely the combined use of heat pump and other heat sources which is perceived to provide a new, flexible heating system. A few emphasized the quality of the heat pump to distribute the hot air from the stove to other parts of the house, highlighting how the two heating technologies jointly produce the desired level of comfort. Many also use a mix of electric heating sources, for example, as indicated in this quote: "I keep on the electric floor heating cables in the entrance at given temperature (controlled by a thermostat), and these will turn off automatically when the pump has provided a satisfactory indoor temperature in the whole house." This demonstrates the way various practices are interlinked, which also resonates with the finding of 
Henning (2000) from Sweden where people stressed the importance of being able to rely on various sources which together provide a high degree of heating flexibility.

\section{Temporal rebound}

The shifts in practices referred to above reflect that the families who have heat pumps tend to keep a higher average indoor temperature in the winter, particularly during the night and when the house is unoccupied. Some also refrain from turning off the heat pump or reducing its thermostatic setting when going away for weekends or even longer periods of time. Although most of our respondents denied that they now keep a higher indoor temperature, the reported higher temperatures during night-time and when not at home reflect a comfort rebound effect. Their "denial" may reflect that people are more conscious of the peaks (which have not increased) rather than average temperatures (which have increased) and/or that their bodies have adjusted. Although a few households reported that they keep the heat pump on all year round, most of our families claimed they have not extended the heating season after having obtained the pump. This contrasts the Danish study (Christensen et al. 2011) and the SSB study in Norway, where people reported to have extended the heating season (Halvorsen and Larsen 2013). In our material, most people said that they tend to start the heating season in September and turn off the heating in May. Some also heat their houses in the summer. In Trønderlag, for example, the outdoor temperature was $11^{\circ} \mathrm{C}$ at the time of the interviews (in June), and the heat pumps were working. As mentioned, five families in our sample (all living in the Oslo area) said that they use or will use the heat pump for cooling in warm periods, and this summer cooling is responsible for an increase in total energy consumption. More significantly, because it involves nearly all the families, the concern for avoiding cold mornings and afternoons contributes to an expansion in total daily heating time. As we discuss below, this trend towards continuous heating is reinforced by expert's advice and people's limited knowledge of the use of thermostatic controls to adjust the temperature. We refer to the expansion of heating time associated with users of heat pumps as the temporal rebound effect.

\section{Spatial rebound}

"It's the circulation of the air", one of our respondents answered when asked to explain why he appreciates the heat pump. The pump had been installed 5 years previously during a major renovation of the house. He said that he had obtained the pump for purely economic reasons, and when asked whether environmental concerns played a role in the decision, he answered no. He believes that he might have saved $10.000 \mathrm{kWh}$ per year (current consumption $28.000 \mathrm{kWh}$ ) compared to what he would have used on electric resistence ovens and heating cables (he also keeps a fireplace). He later added that he often leaves the laundry to dry in front of the heat pump which is located in the living room with an open connection to a large kitchen. He said that the main advantage of the heat pump is its capacity for distributing the heat to all the rooms in the house. Many interviewees pointed out that they liked the circulation provided by the pump, as well as the dryness of the heat produced and the general air quality. A few expressed that the heat pump delivered "clean heat" compared to a wood stove.

The issue of circulating air was brought up and appreciated by most of our respondents, both as a quality in itself and because the circulation is considered to be cost-efficient. For example, one man said: "this is different from the resistance ovens where one gets the dry, burned heat. This [the heat from the pump] is a very nice heat". In addition, one family who was about to install a heat pump highlighted the advantage of keeping the doors open between the bedrooms at night so that they can hear their young children should they wake up in the middle of the night.

The only family in our study who was not content with the circulation function was an elderly couple living in a very old house with many small rooms. They found the direct flow of air from the pump in the kitchen to be uncomfortable and also unhealthy (giving them stiff necks), and they mostly used the pump during night when grandchildren were staying over. Before they retired, they had mainly used the pump during the day when they were at work so that they would return home to a decent temperature in the kitchen (i.e., temporal rebound). But, their overall assessment was that the house was not really suited for a heat pump because the air could not be distributed efficiently.

Air-to-air heat pumps are designed for distributing hot (or cold) air to relatively large spaces in an efficient 
way (cf. script). In contrast to wood stoves and electric panel ovens, which our interviewees referred to as "point sources" that provide intense heat in close approximation to the source, heat pumps are also designed to transport the heat. During installations, the positioning of the device (indoor and outdoor parts) is therefore the most important issue, and installers and users are concerned with placing the pump in a central place in the house (thereby deploying expert knowledge associated with the new item). Homes designed with open solutions (e.g., open space between kitchen and living room) are perceived to be well suited (i.e., fit with the heat pump's technology script). Thus, people who consider renovating and know that they will be installing a heat pump have an incentive for choosing open solutions. As confirmed by many of our respondents, the airto-air pump initiates a practice of keeping doors open between rooms, such as between kitchens, living rooms, entrances, and bedrooms, especially the doors to children's rooms. An important change in heating practice associated with the air-to-air heat pump is an expansion in dimensions of the heated space in the home.

This expansion in heated space is a practice that contributes to rebound. We refer to this expansion as spatial rebound. Together, the increases in daily heating (temporal rebound) and in the amount of heated space (spatial rebound) lead to increases in energy use. These shifts contribute to a change in the ways people establish heating comfort, which underlines the general observation that perceptions of comfort are dynamic and culturally contingent (Wilhite et al. 1996; Shove 2003). Illustrative of this point, one respondent, who was about to have a heat pump installed, reflected that her parents "go crazy when seeing that all the doors are left open and it becomes cold". She grew up in the same house and said she could not remember the house having been as cold as it is today. "It must be something about the way we use the house" she reflected. At the same time, she insisted on their need to keep all the doors open because of their concerns for the children while also complaining that the cold house "makes it embarrassing when people visit and ask to borrow woolen socks". Another man also acknowledged a generational difference in terms of comfort: "When my grandparents used to live here they kept as many doors closed as possible because they only wanted heat in the place they were sitting. So it would become really hot. But we are more used to things being open. It [home space] is supposed to be open and accessible. That kind of generation."
These examples illustrate how the physical characteristics of the heat pump together with their considerations and experiences (practical knowledge) contribute to forming the new heating practices. The close thingperson relationship was also sometimes reflected in people's way of speaking about the pump. They often seemed to assign a substantial amount of agency and personal attributes to the pump itself, for example: "It will sometimes go wild", "it makes some noise, but we have become accustomed to it", "it is a friend", "my sister calls her pump Fredrik". Moreover, at least to the researchers speaking the Oslo dialect, the grammar of the dialect spoken in Trønderlag further underscores the agency aspect of the device, making it seem even more like a person. Here, people use masculine, feminine, or neutral indefinite articles depending on the gender of the noun. Many respondents referred to the pump as a "she" when telling us about how the pump behaves.

\section{Knowledge from the installer, the manual, and other people}

Two sources of knowledge were said to be particularly important to the families in terms of their decision to purchase the heat pump and in their everyday interactions with the pump. First of all, the families' wider social networks had been crucial in the phase when they were considering the purchase (Lutzenhiser 1993, see also Maller et al. 2012 for the importance of social networks when people renovate their homes). All but two families confirmed that they had talked to and received advice from other people (almost always men) in their wider social network, spanning from relatives to friends, neighbors, colleagues, and handymen with whom they were already familiar. The issue for discussion not only seemed to have centered on whether heat pumps are good or not - which is probably related to the fact that heat pumps have become rather common (approximately $25 \%$ of Norwegian families keep heat pumps today - the topics for discussion had also been the characteristics of various heat pump models, such as which models are best suited for temperatures below $-15^{\circ} \mathrm{C}$.

Secondly, advice from the person installing (and maintaining) the heat pump and accompanying manuals (what Akrich 1994 refers to as "de-scription") constitute the main sources of instructive information on how the heat pumps are being used. We know from observing a 
couple of installations that the person checking the premises and mounting the device might not spend too much time explaining how things work and what people should do with the heat pump, but this person nonetheless seems to influence the user patterns in significant ways. The most striking example of such influence concerns the issue of what constitutes a technically optimal usage of the heat pump. Should it regularly be turned on and off or should it run all the time (either by adjusting the temperature manually/automatically or keeping a constant temperature)? The following dialogue is illustrative:

Question: So that means you keep it on twenty three $\left[{ }^{\circ} \mathrm{C}\right]$ day and night?

Wife: Now we do, yes.

Husband: And that was recommended too, he [the installer] was quite clear on that, "you don't mess with that, you just find your temperature and let it work on its own".

Wife: According to him, it would mean more, um - it would use more electricity than we would save by regulating, because...

Husband: It would use quite a lot of energy to speed up the temperature when you have turned it down. So he said "Well if you're going to leave for a week or two then you can turn down the temperature. But you shouldn't do that during the night because it will use too much power in the morning to get the temperature again."

Following the advice, this family and many others in our sample keep the temperature constant during the heating season. Others would say that they use the remote control to manually lower the temperature at night and increase it in the morning (very few use a programming function). What many of these families shared was an explicit reference to the installer having advised them to follow such user patterns, which underlines the significance of this type of expert knowledge. Moreover, the technical advice of not "messing" with the temperature matches people's stated appreciation of the even temperatures and increased comfort provided by the pump, and in the interview setting, they lean on the expert technical advice when legitimizing everyday heating habits. It was beyond the scope of this study to technically assess the effect on consumption of regularly modifying the temperature versus letting it remain constant. The issue also appears unclear among suppliers promoting heat pumps. ${ }^{7}$ As one of our respondents pointed out, the conclusion would probably depend on a range of factors such as outdoor temperature and the amount of structural insulation. Uncertainty on this question discourages people from experimenting with lowering the temperature together with reluctance to learn how to program the heat pump controller and, as discussed, many respondents' preferences for stable temperatures; the technical uncertainty increases the potential for rebound.

\section{Savings}

When accounting for the potential for savings from using a heat pump, many referred to what they had heard: "they say that you may save one third of the costs". On the whole, most respondents with an air-toair heat pump seemed confident that the investment cost would be paid back before the end of the pump's lifetime. The installer we spoke with said that before installing a new pump in a home, he always discusses the potential for saving electricity with the customers. He normally presents a graph showing how much time will elapse before the investment is paid back. Several of our respondents referred to such calculations made by the supplier (ranging from 3 to 5 years for air-to-air heat pumps), and in the many cases where they do not keep track of consumption, they would use such standardized "expectations" for savings when telling us (and their peers/themselves) what they think the economic benefit has been. Some of our interviewees did keep track of their consumption, though, and the costs connected to their former heating sources are of course the reference for calculating financial savings. Some of those who have reduced their consumption of wood and oil think that their electricity consumption has risen or stayed the same. Three families who had reduced electricity consumption presented numbers on how much electricity

\footnotetext{
${ }^{7}$ The Norwegian Heat Pump Association (Norsk varmepumpeforening, NOVAP) gives contradicting advice on this matter. On one of their home pages they refer to Enova's calculations for potential savings (factor 2, 4), and write that "Models which have timer controlled temperature setbacks consume less electricity than those with only a thermostat) http://www. varmepumpeinfo.no/besparelse_for_varmepumpe On another page, NOVAP write that they consider it optimal to keep a stable temperature day and night and point out that daily modification of the temperature may cause damage to the heat pump. http://www. varmepumpeinfo.no/content/varmepumper-demper-energibruken Both sources retrieved 8 August 2014.
} 
they have saved, ranging from 15 to $30 \%$ in reduced consumption. One of these families stated clearly that the only reason for getting the heat pump had been to obtain "more heat", so they have not been zealous about tracking saved electricity and costs.

Many of our interviewees often had a feeling of saving - rather than concrete evidence for doing soas a consequence of using the pump. For example, an elderly couple who has a geothermal heat pump (they invested 15.000 euros (125.000 NOK) showed us their electricity bills (160-190 euros/month) and said that it would probably have been doubled had they used resistance heaters. When we asked how many years they think it will take to pay back the investment, they smiled and said that they do not know, the woman adding "No, but I feel that it has been profitable all the time." Another man who invested in an expensive geothermal system reasoned in a similar way. He said that due to the new heating system, they have reduced electricity consumption by $15.000 \mathrm{kWh}$ per year. However, because they purchased the heat pump at the time of constructing the house, he considers the investment as embedded in the bank loan they took for covering the general project and not as a separate energy saving investment. Thus, when asked about the payback time, he turned his attention to the mortgages/bank payment which has a 25 year period: "So you know, 125.000 NOK over 25 years is not too much per month. So I think the saving came instantly."

With reference to "what they had heard" about the potential for saving, it was interesting to note that a couple of respondents were critical to the general claim that heat pumps lead to saved energy and money. One man has colleagues who work with energy. He said that he thinks that the saving potential of heat pumps is overestimated. Another respondent said that she had read an article about the SSB study on the rebound effect and that she is a little skeptical about the potential for saving that is normally claimed. She is among the few in our study who turns the heat pump on and off on a daily basis. Another family who was about to install a pump referred to the potential for saving while also explicitly acknowledging the potential comfort rebound: "Potentially, we expect a 50 percent reduction of costs, but this will probably be eaten up by increased comfort."

When heat pumps are promoted in Norway, suppliers claim that one may reduce electricity costs by $35 \%$ by shifting to this heating device. Reducing costs is presented as the most important argument for purchasing, and in making the calculations, the heat pump is thought to simply replace other electricity consuming heating sources. As a result, one expects energy savings in terms of reduced electricity consumption and costs. This line of reasoning on the supplier side is presented in Table 2 which also summarizes the heat pump owners' rationale for obtaining the pump and their evaluation of results.

From the table, we can see that people's motivations for obtaining the pump are multiple and include a range of concerns such as comfort, economy, and other aspects. When asked to assess how their own, specific heat pump has affected everyday life, the issue of comfort was accentuated while economic factors were mostly downplayed or left unexamined (though sometimes represented as a "feeling of saving").

We have sought to disentangle the motives and ways which people take heat pumps in use, that is, the ways heat pumps form part of - and modify - the social practices into which they are integrated, whether related to heating, time management, drying clothes, attending to children's safety, or other routines and concerns. Far from observing energy savings as the main drive and result when adapting heat pumps, the families we met

Table 2 Comparison of how heat pumps are promoted by suppliers and how these devices are perceived by the owners/users

\begin{tabular}{|c|c|c|c|}
\hline & Rationale for obtaining heat pump & Means & Results \\
\hline As promoted by suppliers & Energy savings & $\begin{array}{l}\text { Introduce technically efficient heat pump which } \\
\text { provides the same service as the one replaced }\end{array}$ & Energy savings \\
\hline $\begin{array}{l}\text { As seen by owners/users } \\
\text { of heat pumps }\end{array}$ & $\begin{array}{l}\text { Comfort } \\
\text { Save money } \\
\text { Reduce hassle with wood } \\
\text { Avoid oil burner } \\
\text { Find suitable heating or } \\
\text { coolingsolution when } \\
\text { renovating }\end{array}$ & $\begin{array}{l}\text { Introduce heat pump to be used in combination } \\
\text { with existing heating sources which jointly } \\
\text { fulfill the various needs of the family }\end{array}$ & $\begin{array}{l}\text { Increased comfort } \\
\text { Convenience } \\
\text { Flexibility } \\
\text { Improved air quality } \\
\text { Increased safety } \\
\text { Energy savings } \\
\text { Reduced costs }\end{array}$ \\
\hline
\end{tabular}


socially organize the heat pump and other technologies to make them fulfill their daily needs.

\section{Conclusion}

Through the analysis of 28 in-depth interviews and observations of the placement and uses of the heat pump in people's homes, this paper has sought to develop new perspectives on the rebound effect. By studying the moments of change which invite readjustments in perceptions of comfort we have identified two main changes of practice. First, there is a spatial rebound, the extension of the total space of the house that is heated. Second, we identified a temporal rebound, which implies an extension of heating time.

Approximately half of our families introduced the pump in connection with a major house renovation. The embedding of the heat pump purchase as part of a larger renovation camouflages to these users how much energy they might have saved by replacing other heat sources with the pump. Also important with regard to spatial rebound, the embedded agency of the heat pump has observably affected practices. The air-to-air heat pump is designed to produce and transport/circulate air to function optimally; thus, it favors open solutions during renovations and encourages the practice of keeping doors between rooms constantly open and heating (or cooling) larger volumes of space. This is strengthened through the advice and information provided by installers, and it also matches people's preferences for an extension of comfort through the capacity to move from one room to another without experiencing any parts being colder than others. The new type of comfort is even associated by some families as best suited to the younger "free" generation in contrast to members of the older generation who were content to sit next to point sources of heat and to keep the doors closed.

The practical knowledge derived from previous heating practices ("I used to hate entering the cold entrance foyer") is important to the shift to heating more space. Thus, we see how three sources of agency: the heat pump's script, the appeal to expert knowledge associated with the information accompanying the pump, and the practical knowledge people possess together shape the transformation to this new heating practice that involves a larger heated space. We see a clear spatial rebound in that the potential gains from saving electricity by using a more efficient technology is eaten up by the expansion in heated space.

The temporal rebound effect involves using energy for heating (or cooling) during an extended period of time. When coming home to the house or waking up in the morning, the families appreciate entering space with a comfortable temperature instead of having to endure a cool house while waiting for the optimal temperature. People appear to be in a hurry to be comfortable. As a result, most families let the heat pump run constantly in cold periods, including when going away for a weekend or even longer. Similar to the spatial rebound, the sociotechnical script of the pumps contributes to providing this shift, but here, the script for usage is more open to interpretation. It remains an open question whether turning on and off or lowering the temperature (at night-time or during longer periods of time) leads to less consumption or not or if constant heating is technically optimal. It appears that heating practices are formed in the light of ambiguous technical information. Most families contend that keeping a constant temperature is technically optimal, while, at the same time, providing the desired level of comfort.

As a third, residual category, which we label "multipurpose rebound", we clustered other relevant considerations and practices which also contribute to increased energy consumption. This included attending to children at night, maintaining safety and air quality, and conjoint practices such as drying clothes. Another observation confirmed in our study is that energy consumption is socially conditioned (e.g., thinking about children, grandchildren, and guests) and that perceptions of comfort are shifting and culturally contingent (e.g., generational variation). Gender relations and intrahousehold dynamics have not been examined in the present work but are also likely to affect household consumption patterns. ${ }^{8}$

In terms of the potential for promised savings of energy and costs, the results from this study underline that the potential for saving electricity varies considerably between different types of users depending on their existing heating practices. Not surprisingly, the potential for saving electricity was low or negative among families who shifted from oil or mainly wood to heat pumps

\footnotetext{
${ }^{8}$ In this paper, we do not discuss intra-household negotiations related to the purchasing and use of heat pumps. For treatments of this issue, see e.g. Møller Jensen 1990, Henning 2005 and Winther 2012.
} 
and highest among families who replaced electric resistance ovens with heat pumps. The latter shift is what is presumed in the information promoting heat pumps. In our sample, where only a few reported to know the reduced amount of electricity consumption resulting from the use of the heat pump, many developed new heating habits involving the expansion of the home's heated space as well as the time period for heating, and thus, rebound seemed to occur in most cases. The challenge for policy is that heat pumps enable both a reduction in costs and an increase in comfort. Partly because cost reductions are difficult to discern, cost considerations are not significant in the reformation of practices after the acquisition of the heat pump. Many take advantage of the potential to heat more of the house over longer periods of time. The results of our study confirm that rebound in energy use takes place in many homes with installed heat pumps and identifies practices behind energy rebound. We hope that the identification of a temporal and a spatial dimension in comfort rebound, and the demonstration of the interlinkages between various heating practices and other domestic practices shown in this study, clarify the challenges for energy saving policy and identify new targets and objectives for programs aimed at reducing the energy intensity of home heating.

Acknowledgments We thank four anonymous reviewers for providing their valuable comments to an earlier draft. The authors are associated with CREE-the Oslo Centre for Research on Environmentally friendly Energy-which is supported by the Research Council of Norway.

Open Access This article is distributed under the terms of the Creative Commons Attribution License which permits any use, distribution, and reproduction in any medium, provided the original author(s) and the source are credited.

\section{References}

Akrich, M. (1994). The description of technical objects. In W. E. Bijker \& J. Law (Eds.), Shaping technology/building society. Studies in sociotechnical change (pp. 205-224). Cambridge, MA: Massachusetts Institute of Technology Press.

Biswanger, M. (2001). Technological progress and sustainable development: what about the rebound effect? Ecological Economics, 36, 119-132.

Bourdieu, P. (1977). Outline of a theory of practice. Cambridge: Cambridge University Press.

Brannlund, R., Ghalwash, T., \& Norstrom, J. (2007). Increased energy efficiency and the rebound effect: effects on consumption and emissions. Energy Economics, 29(1), 1-17.

Christensen, T., Gram-Hanssen, K., Petersen, P. E., Larsen, T. F., Gudbjerg, E., Rasmussen, L. S., \& Munter, P. (2011). Air-to-air heat pumps: a wolf in sheep's clothing? Proceedings of the 2011 ECEEE Summer Study. Stockholm: European Council for an Energy Efficient Economy.

De Haan, P., Mueller, M., \& Peters, A. (2006). Does the hybrid Toyota Prius lead to rebound effects? Analysis of size and number of cars previously owned by Swiss Prius buyers. Ecological Economics, 58, 592-605.

Dutschke, E., Peters, A., \& Schleich, J. (2013). Rebound effects in residential lighting - conceptual psychological framework and empirical findings. Proceedings of the 2013 ECEEE Summer Study. Stockholm: European Council for an Energy Efficient Economy.

Enova (2013). "Utfasing av oljekjel" (in Norwegian) http://www. enova.no/radgivning/privat/rad-om-produkter-og-losninger/ oppvarmingsalternativ/utfasing-av-oljekjel/utfasing-avoljekjel/508/1252/ Retrieved 26 August 2013.

Fouquet, R., \& Pearson, P. (2012). The long run demand for lighting: elasticities and rebound effects in different phases of economic development. Economics of Energy and Environmental Policy, 1(1), 83-100.

Frondel, M., Ritter, N., \& Vance, C. (2012). Heterogeneity in the rebound: further evidence from Germany. Energy Economics, 34, 461-467.

Gram-Hanssen, K. (2010). Residential heat comfort practices: understanding users. Building Research \& Information, 38(2), 175-186.

Gram-Hanssen, K. (2014). New needs for better understanding of household's energy consumption - behaviour, lifestyle or practices? Architectural Engineering and Design Management, 10(1-2), 91-107.

Halkier, B., Katz-Gerro, T., \& Martens, L. (2011). Applying practice theory to the study of consumption: theoretical and methodological considerations. Journal of Consumer Culture, 11, 4-13.

Halvorsen, B., \& Larsen, B. M. (2013). How do investments in heat pumps affect household energy consumption? Discussion Papers No. 737, April 2013. Norway: Statistics Norway.

Henning, A. (2000). Ambiguous artefacts: solar collectors in Swedish contexts-on processes of cultural modification. Stockholm Studies in Social Anthropology, 44. Department of Social Anthropology, Stockholm University. Stockholm: Almqvist \& Wiksell International.

Henning, A. (2005). Equal couples in equal houses: cultural perspectives on Swedish solar and bio-pellet heating design. In S. Guy \& S. A. Moore (Eds.), Sustainable architectures: cultures and natures in Europe and North America (pp. 89104). New York: Spoon Press.

Herring, H. (2011). Dealing with rebound effects. Proceedings of the 2011 ECEEE Summer Study. Stockholm: European Council for an Energy Efficient Economy.

Hofstetter, P., Madjar, M., \& Ozawa, T. (2006). Happiness and sustainable consumption - psychological and physical rebound effects at work in a tool for sustainable design. International Journal of Life-Cycle Assessment, 11, 105-115. 
Jevons, W. S. (1865). The coal question: an inquiry concerning the progress of the nation, and the probable exhaustion of our coal-mines. London: Macmillan and Co.

Lutzenhiser, L. (1993). Social and behavioral aspects of energy use. Annual Review of Energy and the Environment, 18, 247289.

Maller, C., Horne, R., \& Dalton, T. (2012). Green renovations: intersections of daily routines, housing aspirations and narratives of environmental sustainability. Housing Theory and Society, 29(3), 255-275.

Møller Jensen, J. (1990). Familiens købsbeslutninger - et 'købscenter' perspektiv, Denmark. Erhvervsøkonomisk Tidsskrift, 54(2), 85-91.

Reckwitz, A. (2002). Toward a theory of social practices: a development in culturalist theorizing. European Journal of Social Theory, 5, 243-263.

Shove, E. (2003). Comfort, cleanliness and convenience: the social organization of normality. Oxford, New York: Berg.

Sorrell, S., Dimitropoulos, J., \& Sommerville, M. (2009). Empirical estimates of the direct rebound effect: a review. Energy Policy, 37(4), 1356-71.

Thomas, B., \& Azevedo, I. (2013). Estimating direct and indirect rebound effects for U. S. households with input-output analysis Part 1: theoretical framework. Ecological Economics, 86, 199-210.

Turner, K. (2009). Negative rebound and disinvestment effects in response to an improvement in energy efficiency in the UK economy. Energy Economics, 31(5), 648-666.

Warde, A. (2005). Consumption and theories of practice. Journal of Consumer Culture, 5(2), 131-153.

Wilhite, H. (2008). New thinking on the agentive relationship between end-use technologies and energy-using practices. Energy Efficiency, 1, 121-130.

Wilhite, H. (2013). Energy consumption as cultural practice: implications for the theory and policy of sustainable energy use. In S. Strauss, S. Rupp, \& T. Love (Eds.), Cultures of energy (pp. 60-72). San Francisco: Left Coast Press.

Wilhite, H., Nakagami, H., Masuda, T., Yamaga, Y., \& Haneda, H. (1996). A cross-cultural analysis of household energy-use behavior in Japan and Norway. Energy Policy, 24(9), 795803.

Winther, T. (2012). Negotiating energy and gender: ethnographic illustrations from Zanzibar and Sweden. In K. Bjørkdahl \& K. B. Nielsen (Eds.), Development and environment: practices, theories, policies (pp. 191-207). Oslo: Akademika Publishing. 